\title{
Melanoma of the Uvea pM1a TNM Finding v7
}

National Cancer Institute

\section{Source}

National Cancer Institute. Melanoma of the Uvea pM1a TNM Finding v7. NCI Thesaurus. Code C88713.

Melanoma of the uvea with distant metastasis, with the largest diameter of the largest metastasis measuring $3 \mathrm{~cm}$ or less. (from AJCC 7th Ed.) 